\title{
ALGUNAS NOTAS SOBRE LA PROYECCIÓN LITERARIA EN EL EPISTOLARIO DE PEDRO SALINAS A KATHERINE WHITMORE
}

\author{
Clara Eugenia Peragón LóPez \\ Universidad de Granada
}

\begin{abstract}
Katherine, bendita mía, día bendito para mí, hoy. Llegó tu carta del 11, la de la recepción del libro. [...]. «Tú sabes lo que te mandaba», vida. Lo has sabido perfectamente. Mi libro no era mi libro. Lo que yo te he mandado no eran poemas, no poesía, sino sobre eso, puesto encima de todo, sirviendo la poesía y el libro únicamente como apoyo, como punto de arranque, algo más entrañablemente tuyo y mío, «sólo tuyo y mío», de nadie más, el amor de nuestra vida. No es un libro, es una prenda, una señal material, una memoria, una promesa del amor de nuestras vidas [...]. No es poesía, sólo, no es literatura, no, es vida, vida vivida, y ni críticos, ni historias, ni años podrán jamás juzgar mejor que la criatura por quien esa vida fue vivida, a cuyo lado fue vivida ${ }^{1}$.
\end{abstract}

Si durante muchos años la existencia de la amada en la trilogía amorosa de Pedro Salinas (La voz a ti debida, Razón de amor, Largo lamento) ha sido reducida a un «fenómeno de conciencia» (Leo Spitzer) del poeta, la cita reproducida, entre otros muchos ejemplos, confirma las relaciones entre «mundo real y mundo poético» donde «la realidad maravillosa, múltiple, cargada de elementos poéticos, se yergue e intenta colocarse, colocar su mundo real en ese espacio que los poetas labraron siempre en otro mundo, el suyo, el poético» ${ }^{2}$.

La realidad es que Pedro Salinas conoció a Katherine Prue Reding (1897) durante los cursos de verano de 1932 en la madrileña Residencia de Estudiantes. Tras breves encuentros ese mismo año en Alicante y Barcelona, la profesora de Smith College (Northampton, Massachusetts) volvería a su país prosiguiendo la relación con el poeta de forma epistolar.

${ }^{1}$ Carta 105 (24 de enero de 1934). Pedro SAlinas, Cartas a Katherine Whitmore. Edición y prólogo de Enric Bou (2. ${ }^{a}$ edición), Barcelona, Tusquets, 2002, pp. 235-237.

2 Pedro Salinas, Mundo real y mundo poético, ed. de Christopher Maurer, Valencia, Pre-textos, 1996, p. 17.

Rlit, LXVI, 132 (2004), 465-484 
Entre 1932 y 1934, las cartas fueron muy frecuentes, casi diarias. Katherine volverá a Madrid en el curso 1934-35, época en que la mujer de Salinas descubre el romance e intenta suicidarse, un hecho que impulsará a Katherine a romper la relación viéndose dificultado su propósito con la Guerra Civil y el exilio de Salinas a EE.UU. Una vez finalizada la estancia de la profesora en México (1937-38), ésta decide casarse con Brewer Whitmore, (de quien toma el apellido por el que se la conoce) compañero de Smith College. A partir de este momento, aunque mantendrían algún encuentro fugaz, ambos se distanciaron bastante viéndose por última vez en 1951, unos meses antes de la muerte del poeta.

En su «Defensa de la carta misiva y de la correspondencia epistolar», interesante ensayo incluido en El Defensor (1948), Pedro Salinas se refiere a la escritura de la carta como una «ocupación exquisita, servidora de un placer espiritual», de un querer comunicarse y establecer un diálogo con la persona ausente («He aquí el círculo social mínimo de la carta, dos personas. Es el número de la perfecta intimidad, el más semejante al número del amor») ${ }^{3}$ pues «distancias y ausencias son tinieblas y envuelven por igual al presente y al ausente. Un no poder verse material, engendra como un espiritual al no verse. Las gentes, de lejos, mueren a la visión; y empiezan a agonizar en la memoria de los corazones. La carta actúa como luz, porque luz es el verbo» ${ }^{4}$.

Sin duda, la escritura de una carta es una tarea solitaria, privada, que pasa a ser «compartida» y «convivida» en el momento de la lectura por parte del receptor iniciándose así «un entenderse sin oírse, un quererse sin tactos, un mirarse sin presencia, en los trasuntos de la persona que llamamos, recuerdo, imagen, alma» ${ }^{5}$.

Si la tradición dominante acercaba arte epistolar y conversación, doctrinas como la del Pseudo-Demetrio ponen de relieve la instancia de la escritura como rasgo distintivo del género. Así pues, «el diálogo imita una conversación improvisada pero la carta es una forma de escritura que se envía a alguien a modo de regalo» ${ }^{6}$.

Del mismo modo, Salinas no pretende reducir la carta a una conversación a distancia supliendo un diálogo imposible. El poeta considera que «asimilar escritura epistolar a conversación es desentenderse de la originalidad pasmosa, de la novedad absoluta con que aumenta la carta este negocio de las relaciones entre persona y persona. Es no fijarse en la mina

${ }^{3}$ Pedro Salinas, Ensayos completos, vol. 2, Madrid, Taurus, 1983, p. 233.

${ }^{4}$ Ibid., p. 225.

${ }^{5}$ Ibíd., p. 228.

${ }^{6}$ Cito según Claudio GullléN, «Al borde de la literariedad: literatura y epistolaridad», Tropelías. Revista de Teoría de la Literatura y Literatura comparada, 1991, pp. 71-92. 
propia, el venero intacto, que la carta beneficia, y cuyas preciosidades dispensa a la humanidad, sin traba» ${ }^{7}$.

La carta, según escribe el poeta el 16 de diciembre de 1932, pasa por diferentes estados de lectura («Primero recorrerla con la vista, lectura material, pero ya captando al pasar lo más esencial. Luego leerla con el recuerdo. Ya nos hemos dejado la carta en casa, estamos en nuestras obligaciones, vamos por la calle, o muchas veces se tiene un libro en la mano, parece que se lee el libro y no es así: la vista, distraída, se aparta del libro impreso, y lo que leemos en realidad es aquella carta que está en casa o en el bolsillo. [...] Luego viene la tercera fase: que es volver a leer materialmente, con los ojos otra vez, la carta. Es mucho más fecunda que la primera. Ya la conocemos, ya nos detenemos en los pasajes más queridos, y acaso descubrimos otros nuevos. Es la perfección de la lectura, ya total, pasada por completo por el alma y por la vista. Y después no hay sino dejarla ya, que se pose en la memoria, que grabe allí lo que más hondamente impresionó, que se incorpore a nuestra vida: ya la hemos hecho nuestra» $)^{8}$ y se inserta dentro de un «ritmo» y tiempo propios que, en muchos casos, acercan el conjunto a la novela epistolar. Es lo que Claudio Guillén ha denominado «la ilusión de la no-ficcionalidad», es decir, percibimos una ficción dentro de lo que no lo es, pues «tratándose de la carta, es obvio que normalmente ésta no supone una construcción ficticio-narrativa y desde tal ángulo no aspira consciente o explícitamente a la literariedad que la novela de entrada consigue» ${ }^{9}$. Sin embargo, «en los géneros epistolares el impulso del lenguaje y el progreso de la escritura misma han demostrado tener muchas veces consecuencias de carácter relativamente ficticio» ${ }^{10}$ al existir una cierta «liberación del marco semántico convencional» ${ }^{11}$.

Estas cartas, como muchas de las escritas por Pedro Salinas, reflejan muy claramente su pasión por la escritura convirtiéndolas en verdaderos textos literarios. Si Salinas tenía como principal objetivo transmitir su amor apasionado a Katherine Whitmore, hacerla partícipe de sus sentimientos más íntimos, las cartas requerían un esfuerzo y dedicación especial, además de un tiempo considerable, como lo prueba su larga extensión. Tal conciencia de la lengua, derivada de su integridad personal y artística, podría llevar a pensar a algunos que, en el fondo, la intención del autor era que algún día tales cartas vieran la luz. Salinas afirma al respecto:

\footnotetext{
7 «Defensa de la carta misiva...» (cit.), p. 228.

${ }^{8}$ Carta 44 (16 de diciembre de 1932), pp. 110-111.

9 Art. cit., p. 75 .

${ }^{10}$ Ibíd.

11 Ibíd., p. 77. Sobre el mismo tema cfr., del mismo autor, «El pacto epistolar: las cartas como ficciones», Revista de Occidente, octubre, 1997, pp. 76-98.
} 
[...] la carta es terreno tan resbaladizo, que la intención estrictamente humana, de comunicarse con otra persona por escrito, al tener que servirse inevitablemente del lenguaje, puede deslizarse al otro lado de las fronteras de lo privativo, sin que el autor se de cuenta apenas, y convertirse en intención literaria. Porque el lenguaje tiene sus misteriosas leyes de hermosura, sus secretas exigencias, también, que tira del que escribe. Es muy difícil que la persona que se pone a escribir no sienta, dése o no cuenta de ello, prurito de hacerlo bien, de escribir bien. Y si lo logra, la pena que le aguarda, ya sabemos cuál es; la caída de Ícaro, de los cielos limpios - lo privado- a las aguas dudosas -la publicidad ${ }^{12}$.

Asimismo, en las cartas se percibe la utilización de un lenguaje metacrítico y una constante conciencia teórica que hace preguntarse al poeta por la calidad de sus esfuerzos así como por la conveniencia de la materia tratada y del estilo elegido ${ }^{13}$ :

A veces tengo miedo de que mis cartas te parezcan demasiado «serias», «graves», que no veas en ellas [ilegible] ligero. Y me pregunto: «¿Le gustará esto?» ${ }^{14}$

Por otra parte, la forma externa de la carta también será objeto de alusiones por parte del poeta. Además de a su ya conocida costumbre de utilizar la tinta verde, Salinas alude en algunas de las cartas a su mala letra (« ¿ Te vas acostumbrando ya a mi escritura, a esta terrible letra mía? ¡Pobrecita! Tú que has aprendido tantas cosas, latín, alemán, francés, ¡qué sé yo!, tener ahora que aprender a leer») ${ }^{15}$, a la escritura de algunas de las cartas a máquina ( «Perdona esta carta, así a máquina. Pero tengo un pulso tan alterado que me es materialmente «imposible» escribir sino así. No lo volveré a hacer») ${ }^{16}$, al papel utilizado («Ayer, en Alicante, pensamiento: 'Me dijo que la gustaba el papel amarillo. Buscaré papel amarillo'. Ya está. Me gusta dedicarte todo, desde el más profundo sentimiento a esta pequeñez, un tono de papel») ${ }^{17}$...

De la misma forma, Salinas también desvelará algunos detalles sobre las cartas enviadas por Katherine ( $\ll_{i}$ Cómo me encantan tus cartas! Y isabes, además, que tu español es cada día mejor? Saltan de vez en cuando en tus cartas expresiones graciosas y muy tuyas. Mira, hace unos días «Pecado, pecadísimo». Ayer: «otoños bellos, desagravio del invierno». Y una frase que me gusta aún más que todas: «... esta carta tardará en llegar a tus manos. ¡Tus manos! ¡Quién fuera carta!». No, no es que sean frases profundas, no es que sean pensamientos trascendentales, no. Son más, son

\footnotetext{
${ }^{12}$ Pedro SAlinAs, «Defensa de la carta misiva...» (cit), p. 238.

${ }^{13}$ Claudio GullLÉN, «Al borde de la literariedad...» (cit.), p. 80.

${ }^{14}$ Carta 8 (14 de agosto de 1932), p. 53.

${ }^{15}$ Carta 3 (3 de agosto de 1932), pp. 44-45.

${ }^{16}$ Carta 12 (27 de agosto de 1932), p. 58.

${ }_{17}$ Carta 15 (30 de agosto de 1932), p. 65.
} 
expresiones felices, directas y graciosas exquisitamente femeninas de esa alma que yo te adoro. Son tan vivas, tan directas. $¡ Y$ al propio tiempo tan refinadamente tuyas! ¡Katherine, hoy por hoy eres el autor que más me gusta! $\mathrm{Y}$ te aseguro que por una página tuya dejaría la obra maestra») ${ }^{18}$.

En cualquier caso, debemos situar la carta en el ámbito de lo íntimo, lo privado. Salinas advierte sobre la necesidad de distinguir las cartas públicas de las privadas y cómo la publicación de estas últimas no las convierte en públicas puesto que la primitiva intención del autor, que es lo que las diferencia, no varía. Se refiere a ellas como «cartas traicionadas».

Quizá este tipo de consideraciones unidas al temor a ser conocida y a sacar a la luz una intimidad celosamente guardada impulsaron a Katherine Whitmore a no facilitar el acceso a estas 354 cartas y 144 poemas ${ }^{19}$ hasta el año 1979 en que, a instancias de Jorge Guillén, donó la colección a la Houghton Library de la Universidad de Harvard acompañada de un valioso texto en el que se reconoce como «La amada de Pedro Salinas».

El epistolario que Pedro Salinas dirige a Katherine Whitmore va a revelar un doble aspecto documental y literario ${ }^{20}$. Si evidente es la relación de estas cartas con su obra literaria ${ }^{21}$, en concreto con su poesía amorosa, las cartas se convierten también en una fuente excepcional para conocer los avatares de la vida del escritor, su día a día. Es decir, que además de acercarnos al proceso de creación de uno de los mejores poemarios de temática amorosa del siglo $\mathrm{XX}$, encontraremos una serie de detalles de carácter documental sobre la historia de la España de su tiempo (condiciones de la vida académica en la España de 1932 ${ }^{22}$; los avatares de la fundación de la Universidad Internacional ${ }^{23}$; las oposi-

${ }_{18}$ Carta 31 (8 de noviembre de 1932), p. 91. También carta 37 (15 de noviembre de 1932), pp. 101-103.

${ }^{19}$ Esta cifra corresponde a la colección completa. Enric Bou, por su parte, presenta en su edición del epistolario saliniano una selección de 151 cartas siguiendo tres criterios básicos según él mismo señala: el interés literario, la información acerca de aspectos biográficos y la calidad estrictamente literaria.

${ }^{20}$ Sobre este tema véase Enric Bou, «Escritura y voz: las cartas de Pedro Salinas», Revista de Occidente, noviembre de 1991, pp. 13-24.

21 «Tratándose de cartas de escritores - señala Andrés Soria Olmedo- además, la correspondencia establece una relación con las obras escritas para el público que dista de ser simple; las cartas funcionan longitudinalmente, como avant-cuisine, a un tiempo temática y estilística, de las obras para el público, como puentes entre lo vivido y la formalización que se plasma en las obras, iluminando muchos enclaves del mundo espiritual y anímico de sus autores, incluida la puesta en escena de procesos imaginarios no conscientes. Las cartas privadas siempre presentan zonas de sombra: pasto de la crítica psicoanalítica, proporcionan otra incitación posible para el lector», «Dos voces a nivel», Pedro Salinas-Jorge Guillén, Correspondencia (1923-1951), Barcelona, Tusquets, Colección Marginales 120, 1992, p. 12.

${ }^{22}$ Carta 50 (25 de diciembre de 1932), pp. 121-123.

${ }^{23}$ Carta 62 (30 de enero de 1933), pp. 145-146; Carta 78 (23 de febrero de 1933), pp. 177-179; Carta 98 (18 de mayo de 1933), pp. 219-221; Carta 100 (7 de septiembre de 1933), pp. 223-225. 
ciones $^{24}$; el Índice Literario. Archivos de Literatura Contemporánea ${ }^{25}$; la historia literaria que se practicaba en la época ${ }^{26}$, el arte del siglo $\mathrm{XX}^{27} \ldots$ ) y de carácter biográfico (comentarios sobre su infancia ${ }^{28}$, su familia ${ }^{29}$, su amistad con Jorge Guillén ${ }^{30} \ldots$..).

En el «Prólogo» a las Poesías completas ${ }^{31}$ de Pedro Salinas, su gran amigo Jorge Guillén afirma que La voz a ti debida (1933) nos sitúa ante un amor donde «todo queda exaltado: la pasión, la ternura, la sensualidad. En cuerpo y alma los amantes son amantes con ahínco permanente» y vivirán su amor en un universo cerrado sólo habitado por ellos.

A partir de su primer encuentro en 1932, la voz al amor debida es lo único que se dejará oír tanto en su poesía como en las cartas dirigidas a su amante. En tales cartas, las referencias a $L a$ voz a ti debida son mucho más numerosas respecto a Razón de amor y Largo lamento, aunque también concretaremos referencias a estos últimos libros.

La voz a ti debida es él libro que Salinas considera más conseguido, más suyo, mejor dicho «nuestro», es el libro en el que se plasma el conocimiento primero, el flechazo, el arrebato, y en el que el poeta concibe el amor «como proceso de autoconocimiento del yo a partir del tú» ${ }^{32}$, un tú innombrado en los poemas y con nombre propio en las cartas: Katherine, que produce en Salinas un sentimiento definido en una carta fechada el 17 de agosto de 1932:

¡Vertigo, pasión, fuerza arrebatadora, sensación de cosa leve arrastrada por un poder indominable, que es, al mismo tiempo, la propia voluntad! ¡Loco, sí, absurdo, loco en la terrible apariencia de la cordura, con el oficio de ser cuerdo! Tú liberadora, salvadora, divina depositaria de la sal de la vida, la locura,

${ }^{24}$ Carta 60 (25 de enero de 1933), pp. 141-143.

${ }^{25}$ Carta 50 (cit); Carta 75 (18 de febrero de 1933), pp. 172-175.

${ }^{26}$ Carta 75 (cit.).

${ }^{27}$ Carta 86 (13 de marzo de 1933), pp. 194-196.

${ }^{28}$ Carta 49 (24-25 de diciembre de 1932), pp. 119-121.

${ }^{29}$ Carta 14 (30 de agosto de 1932), pp. 63-64; Carta 68 (7 de febrero de 1933), pp. 157-159; Carta 75 (cit.); Carta 111 (14 de marzo de 1934), pp. 253-256; Carta 150 (9 de febrero de 1946), pp. 367-370.

${ }^{30}$ Carta 135 (17 de septiembre de 1938), pp. 317-320; Carta 140 (1 de febrero de 1939), pp. 335-338; Carta 141 (26 de febrero de 1939), pp. 339-341.

${ }^{31}$ Barcelona, Seix Barral, 1971, p. 18.

${ }^{32}$ Pedro Salinas, La voz a ti debida, Razón de amor, Largo lamento. Edición de Montserrat Escartín, Madrid, Cátedra, 1999, pp. 12-13. Seguimos esta edición para las citas. Sobre La voz a ti debida resultan muy interesantes los siguientes artículos: Luce LÓPEZ BARALT, «Melibeo soy: La voz a ti debida de Pedro Salinas como reflexión ontológica», La Torre (N.E.). Revista de la Universidad de Puerto Rico, octubre-diciembre, 1994, pp. 563-599; Antonio CARREÑo, «Los mitos del yo lírico: La voz a ti debida de Pedro Salinas», Torre (N.E.). Revista de la Universidad de Puerto Rico, abril-junio, 1993, pp. 189-212; Juan MARICHAL, «Pedro Salinas: la voz a la confidencia debida», Revista de Occidente, 1965, pp. 154-170. 
la embriaguez espiritual, la superación de sí mismo, la ascensión hacia lo más alto [...]. El contacto contigo, el encuentro contigo, me ha lanzado al mundo otra vez. Y salgo a él con el mismo ímpetu, el mismo delirio, el mismo arrebatado afán que tú me conoces ${ }^{33}$.

Para Salinas, con la amada nace la belleza del mundo, la vida, lo cual nos remite a los primeros versos de $L a$ voz:

$$
\begin{aligned}
& \text { Tú vives siempre en tus actos. } \\
& \text { Con la punta de tus dedos } \\
& \text { pulsas el mundo, le arrancas } \\
& \text { auroras, triunfos, colores, } \\
& \text { alegrías: es tu música. } \\
& \text { La vida es lo que tú tocas }{ }^{34} \text {. }
\end{aligned}
$$

El 30 de agosto de 1932, Salinas hace balance en su carta de todo lo vivido con su amada durante el poco tiempo que llevan juntos: «Nuestro encuentro fue la anécdota, fue el hecho casual. Pero ya nos habíamos encontrado antes, ya estábamos reunidos, en un común querer reunirnos, no sé desde cuando. Por eso, amor, no ha habido entre nosotros vacilación, duda, esperanza, aplazamiento» ${ }^{35}$. Y es que el poeta no necesita tiempo para conocer a su amada. "Conocerse es el relámpago», reza uno de sus versos ${ }^{36}$.

Esa alegría, el gozo ante el encuentro del amor, se materializan en varios de los poemas de La voz: "Y súbita, de pronto,/ porque sí, la alegría./. Sola, porque ella quiso,/ vino. Tan vertical,/ tan gracia inesperada,/ tan dádiva caída,/ que no puedo creer que sea para mí» (Poema 8) ${ }^{37}$; «Para vivir no quiero/ islas, palacios, torres./ ¿Qué alegría más alta: / vivir en los pronombres!» (Poema 14) ${ }^{38}$; «De prisa, la alegría,/ atropellada, loca./ Bacante disparada/ del arco más casual/ contra el cielo y el suelo». (Poema 15$)^{39}$; «Todo dice que sí./ Sí del cielo, lo azul,/ y sí, lo azul del mar,/ mares, cielos, azules/ con espumas y brisas,/ júbilos monosílabos/ repiten sin parar». (Poema 16) ${ }^{40}$; «iSí, todo con exceso:/ la luz, la vida, el mar!/ Plural todo, plural,/ luces, vidas y mares./ A subir, a ascender/ de docenas a cientos,/ de cientos a millar,/ en una jubilosa/ repetición sin fin,/ de tu amor, unidad». (Poema 19) ${ }^{41}$; "Qué alegría, vivir/ sintiéndose vivido./ Rendirse/ a la gran certidumbre, oscuramente,/ de que otro ser, fuera de mí, muy lejos,/ me está viviendo». (Poema 21) ${ }^{42}$.

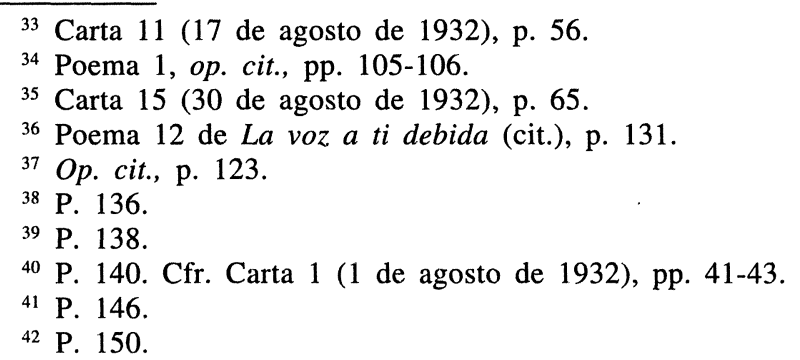


El amor y la ausencia («inmenso lecho de distancias») son dos de los temas que se intercalan en el epistolario saliniano de forma constante. Si el amor persiste, la ausencia implica una idealización de la amada que el poeta intentará sustituir por la real: «Sumirme más y más en la contemplación interior de lo que me falta ante los sentidos. Suplir, reemplazar la forma que no veo, el ser que no tengo, por la forma ideal que pienso, por el ser ideal que quiero. Tú, ideal y real, a la vez, real en tu idealidad, ideal en tu realidad, amor, Katherine» ${ }^{43}$.

Sin embargo, la constatación por parte del poeta de la distancia psicológica que le separa de su amada hará surgir todo un mundo de «sombras» que no son sino celos, desconfianza y dudas. Es «la felicidad del yo alternando con su desazón al verse ante un futuro incierto y en manos de una amada inconstante; ya que, salvando momentos de dicha en que la pareja alcanza el clímax de lo soñado, la inseguridad sume al enamorado en un estado de frustración, soledad y espera» ${ }^{44}$.

El poeta quisiera sujetar el amor, a la amada que lo simboliza y teme, y así se lo hace saber en numerosas cartas, que éste se acabe ${ }^{45}$ :

\begin{abstract}
Miedo de cada día, de cada minuto. ¿Pueril, sentimental? No lo sé, ni me importa. Pero, ¡qué terror, pensar que en este instante, en esta hora, en no sé dónde, el olvido esté trabajando contra mí, está deshaciéndome! Di mucho, en medio de la noche, lo pienso, a veces. Surge la pregunta angustiosa. «iMe estará olvidando, ahora, ahora, en este instante?» ¡Qué sensación de morir, de morir lejos de sí mismo, de estarse muriendo lejos, mientras se sigue muriendo aquí! Es no saber si se está vivo o muerto, si arrastra uno consigo un cuerpo, un fantasma, un alma, no lo sé ${ }^{46}$.
\end{abstract}

La intensa vida social de Katherine, despierta en el poeta unos desmesurados celos que llega a confesarle en alguna ocasión: «Y todos esos seres, familia, amigos, me dan envidia, porque ellos tienen lo que a mí me falta y acaso no lo aprecian. Toda esa vida exterior tuya está para mí habitada de fantasmas. ¿No te robará un día un fantasma? Yo no puedo luchar con ellos, porque no los conozco, no estoy a su lado. Y tengo un miedo cósmico a todo el mundo, a todo lo que te puede arrebatar de mi amor. [...]. Es mi angustia, mi famosa angustia, el temor a perderte» ${ }^{47}$.

${ }^{43}$ Carta 14 (30 de agosto de 1932), p. 63.

${ }^{44}$ Montserrat EsCARTín, op. cit, p. 25.

${ }^{45}$ Cfr. Carlos Feal Deibe, La poesía de Pedro Salinas, Madrid, Gredos, 1965.

${ }^{46}$ Carta 4 (7 de agosto de 1932), pp. 46-47. Es éste un sentimiento también plasmado en sus versos (Poema 6 de La voz a ti debida, p. 119):

Miedo. De ti. Quererte

es el más alto riesgo.

Múltiples, tú y tu vida.

${ }^{47}$ Carta 33 (10 de noviembre de 1932), p. 94 
Este obsesivo sentimiento le lleva a no reconocer a su amada, un ser cambiante en un mundo frívolo que no le corresponde, una «persona social, superficial, común que existe para los otros» ${ }^{48}$ : «Ahí, detrás de la risa,/ ya no se te conoce. Vas y vienes, resbalas/ por un mundo de valses/ helados, cuesta abajo;/ y al pasar, los caprichos,/ los prontos te arrebatan/ besos sin vocación,/a ti, la momentánea/ cautiva de lo fácil./ «iQué alegre!», dicen todos./ $\mathrm{Y}$ es que entonces estás/ queriendo ser tú otra,/ pareciéndote tanto/ a ti misma, que tengo/ miedo a perderte, así» ${ }^{49}$.

Puesto que lo cotidiano es lo que atormenta al poeta, se hace necesaria la creación de un mundo no real, un trasmundo ${ }^{50}$, un mundo de amor sólo habitado por los amantes ( $\mathrm{El}$ otro es alrededores») ${ }^{51}$.

En este nuevo mundo creado por el poeta se impone un metafórico sentido ascensional, la horizontalidad frente a la verticalidad del mundo real ${ }^{52}$, así como una medición exhaustiva de un tiempo que el poeta querría infinito ${ }^{53}$ y que en algunos poemas de $L a v o z$ adquiere un sentido metafísico:

48 Jorge Guillén, op. cit., p. 20.

${ }^{49}$ Poema 11 de La Voz (cit), p. 129.

${ }^{50}$ En su edición de la trilogía amorosa de Salinas, Montserrat Escartín advierte: «Dado que todo lo observable tiene un sentido trascendente, escondido, su verdadera esencia se ofrecerá sólo al observador amorosamente aplicado. De ahí el uso frecuente de términos como trasnoche, trasamor..., y otros neologismos que hablan de esa dualidad que ha sido motivo repetido en toda la obra de Salinas: el mundo de acá y el de allá; lo aparente y lo real; y del consecuente vaivén entre conocer e ignorar, viendo la verdad y la mentira como aspectos complementarios de la realidad», pp. 16-17.

${ }^{51}$ Carta 71 (13 de febrero de 1933), p. 164.

52 «Tendido boca arriba, mirando ¿adónde? A un cielo que se llama Katherine Reding, a un mundo que se llama Katherine Reding, a un pasado, a un mañana, que se llama Katherine Reding. ¡Qué bien se está, así boca arriba, horizontal, solo! [...]. La vida es entonces forma del deseo. Suspensión de la ley del día, de las normas de la luz y las medidas, gran huida, gran fuga, al campo de lo querido, de lo ansiado. La noche lo permite todo. Todo. ¡Qué gran compensación a los deberes, a los quehaceres diurnos, esa formidable entrega de la noche a nuestra vida interior. [...]. Luego, de pronto ha llegado la luz. El día. La verdad. Necesidad de ponerse en pie. Verticalidad», Carta 13 (28 de agosto de 1932), pp. 61-62. Sobre este tema escribe Carlos Feal Deibe: «La quietud se representa también en los versos de Salinas por lo horizontal. Horizontal es la postura que tomamos al tendernos, cuando descansamos. [...]. La noche, aliada del amor (reveladora del alma), es, ella misma, horizontal [...]. A lo horizontal se opone lo vertical: «estar de pie». Es ésta la actitud que, normalmente, observamos de día, y ya sabemos que el día oculta, mejor que nada, el alma», op. cit., pp. 111-112. El poema 30 de La voz es muy representativo al respecto: «... Horizontal es la noche/ en el mar, gran masa trémula/ sobre la tierra acostada,/ vencida sobre la playa./ El estar de pie, mentira:/ sólo correr o tenderse./ Y lo que tú y yo queremos/ y el día - ya tan cansado/ de estar con su luz, derecho- / es que nos llegue, viviendo/ y con temblor de morir,/ en lo más alto del beso,/ ese quedarse rendidos/ por el amor más ingrávido,/ al peso de ser de tierra,/ materia, carne de vida», pp. 169-170.

53 «Katherine, ¿No crees tú que hay en la vida dos clases de tiempo? Uno el tiempo nuestro, personificado, vivido, otro el tiempo absoluto, abstracto, impersonal. [...]. Vivi- 


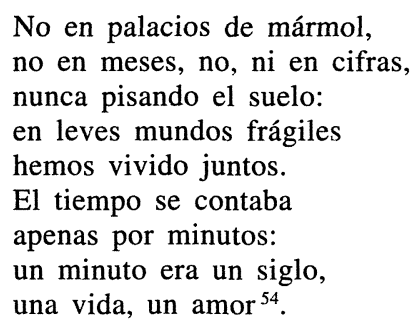

El epistolario a Katherine Whitmore, ya lo hemos adelantado en páginas precedentes, es también un espacio en el que el poeta da cumplida cuenta a su amada de todos los avatares respecto al proceso de gestación y publicación de sus poemas.

A finales de diciembre de 1932, Salinas escribe a Katherine comunicándole su pretensión de marcharse a Alicante («en busca de sol y tranquilidad, a ese mismo hotel donde tú pasaste una noche y donde te encontré una mañana inolvidable, con mi expresión de rostro también inolvidable») ${ }^{55}$ donde se llevará sus papeles, sus notas sobre los versos («casi todas surgidas o sugeridas por tus cartas o mis cartas»), así como un drama medio hecho titulado La cama de matrimonio que el poeta ya tenía proyectado desde el año 1930.

Parece ser que el poema 18 de $L a$ voz pudo ser escrito por Salinas durante estos cuatro días, evocando los que pasó con Katherine en el Peñón de Ifach poco tiempo después de conocerse:

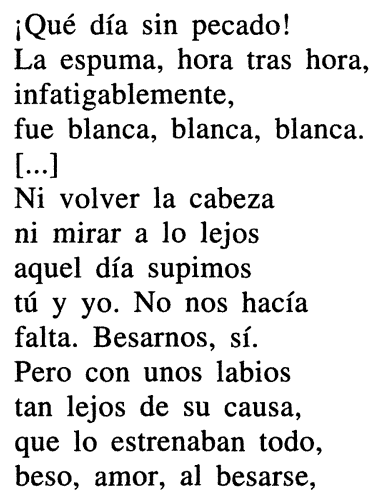

mos nuestro tiempo, el que hemos convertido en posesión total nuestra porque lo hemos dominado con nuestra personalidad. Y ese tiempo no se cuenta en relojes ni calendarios. No sólo el amor sino todas las cosas más finas del alma tienen su temporalidad especial, su cronología inconfundible». Carta 64 (2 de febrero de 1933), p. 150.

${ }^{54}$ Poema 65, op. cit., p. 234.

55 Carta 50 ( 25 de diciembre de 1932), pp. 121-123. 
sin tener que pedir
perdón a nadie, a nada ${ }^{56}$.

Poco más tarde, el 5 de enero de 1933, el poeta explicará el significado del verso de Shelley («Thou Wonder, and thou Beauty and thou Terror») que incluirá como lema de $L a$ voz y que representa, según apunta Concha Zardoya, «la dimensión del amor» en un libro en el que los poemas son «verdaderos ensayos amorosos, en los cuales aparecen todos los aspectos del amor» ${ }^{57}$. «Y esta trimembración - señala Dámaso Alonsocorresponde casi perfectamente al contenido del libro: maravilla y gozo del amante; belleza y gloria de la unión; temor ante la imposibilidad de la unión perfecta y desolación del apartamiento amoroso; misterios gozosos, gloriosos y dolorosos del amor» ${ }^{58}$.

El poeta confiesa a su amada su preocupación por la combinación que ve en ella de fortaleza y debilidad. «Te siento fuerte - escribe-, te veo fuerte, mucho más que yo. Me sé infinitamente débil a tu lado» ${ }^{59}$.

En otra ocasión, el verso de Shelley vuelve a ser referido por Salinas que se pregunta:

¿Por qué extraño misterio del alma ese verso de Shelley se me quedó allí, en mi mente, «olvidado», pero "presente» (¿comprendes?) sin recordarlo en sus términos, pero con la vívida impresión de su sentido? Ese verso, vamos, no el verso, sino lo que expresaba era para mí la forma más honda del amor, no revelado. Como un presagio, como un anuncio, como un trasmundo. [...]. Te repito que tu amor me ha ascendido, me ha elevado. ¿De qué? ¿A qué? No es «de» algo, «a» algo. No es con un fin. Es puramente «de ser». Mi «ser» es más alto, ahora. Todo más alto. Y se ha intensificado todo en esa altura. El dolor es más agudo allí. Y el gozo más cegador e intenso ${ }^{60}$.

$\mathrm{Y}$ es que, como argumenta P.B. Shelley muy al hilo de lo afirmado por Salinas, «Pena, terror, angustia, hasta desesperación, son a menudo las expresiones de una aproximación al bien más alto [...]. El placer que está en la tristeza es más dulce que el placer del placer mismo» ${ }^{61}$.

${ }^{56}$ Op. cit., pp. 144-145. Años más tarde, el poeta evocaría en una de sus cartas el momento inspirador del citado poema: «[...] nos sentamos en un sendero del peñón, cara al mar, te abracé, y mis ojos, queriendo prenderse a algo exterior, que le recordase siempre ese momento, se fijaron en tu traje, en esa floración, al parecer insignificante, de uno de tantos trajes. Ésa fue la semilla del poema. Allí empezó, aunque no sabía, ni supe en mucho tiempo, que iba a escribirlo. Quedó en mi alma, sembrada, y un día floreció». Carta 130 (3 de junio de 1938), p. 300.

57 C. ZARdoYA, «La otra realidad de Pedro Salinas», en A. P. DeBiCKI, (ed.) Pedro Salinas, Madrid, Taurus, 1976, p. 72.

58 Dámaso Alonso, «La voz a ti debida», Diablo Mundo, 6, 2 de junio de 1934, pp. 3-4.

59 Carta 53 (5 de enero de 1933), p. 126.

${ }^{60}$ Carta 58 (23 de enero de 1933), p. 137.

61 P. B. Shelley, Defensa de la poesía, Barcelona, ed. Península/ ed. 62, 1986, p. 55. 
Si la carta que el 2 de febrero (1933) Salinas envía a Katherine ilustra a la perfección los verdaderos y profundos sentimientos del poeta ${ }^{62}$, un día después vuelve a escribirle sobre el mismo tema pero en relación con el libro en preparación, La voz a ti debida. Salinas vuelve a poner de manifiesto el sentido ascensional que domina toda su obra:

Porque amar no es sino una forma de vivir pero «en elevación». Por eso es lo más difícil. Va contra la gravedad. Me han gustado siempre las cosas «ascensionales», «upwards», las torres, los surtidores, los árboles altos y puntiagudos, el cántico, la flecha. Todo lo que no se resigna a un nivel, lo que rompe el módulo medio, como El Greco. [...]. Mi poesía, antes, jugaba a aceptar y no aceptar el nivel, a escaparse a ratos y a conformarse otros con las cosas de la tierra como son. Había «distracciones», «dudas». Pero el libro nuestro ${ }^{63}$, Katherine, es el gran «salto» hacia arriba, en la «unidad» absoluta de atmósfera, de nivel, es mi poesía «en elevación», en tu amor $^{64}$.

en clara correspondencia con algunos de los futuros versos del poema 24 de Razón de amor:

Cuando te digo: «alta»

no pienso en proporciones, en medidas:

Incomparablemente te lo digo.

Alta la luz, el aire, el ave;

alta, tú, de otro modo ${ }^{65}$.

Las explicaciones sobre el sentido último de muchos de los poemas de La voz son una constante a lo largo de todo el epistolario.

El 19 de marzo de 1933 Salinas escribe sobre el poema 17 de $L a$ voz - ha adivinado Enric Bou en su espléndida edición de las cartas- que en ese momento corrige y al que da forma definitiva («Amor, amor, catástrofe./iQué hundimiento del mundo!/ Un gran horror a techos/ quiebra colum-

${ }^{62}$ «No sólo nos amamos, Katherine, nos comprendemos. Creo que no se dará en nosotros nunca esa división tan grave entre personas que se quieren y no se comprenden, ese desgarramiento, y sobre todo esa necesidad de divorciar en uno mismo dos cualidades, inteligencia y amor, y dejar que duerma una mientras otra funciona. ¡Triste cosa, admirar a una mujer, sentirse atraído por ella, únicamente por su belleza, por su atractivo físico, y tener que acallar nuestro gusto de inteligencia al ir hacia ella! [...] ¡Con qué poco se contentan las gentes en eso que llaman amor! Les basta con una leve coincidencia de gustos superficiales, de intereses económicos o de simpatía externa, o con el placer físico de la otra persona recibido, para decir que aman y son amados [...]. Katherine, yo antes de decirte que te quiero, mido muy bien la profundidad de esa palabra. Bajo hasta su fondo, como al fondo de una mina, y regreso seguro de lo que digo: la quiero. Simpatizo con ella, me divierto con ella, pienso en ella, sufro con ella, gozo con ella, hablo, callo, paseo, me estoy quieto mirándola a los ojos, hasta en las diferencias me encuentro con ella». Carta 64 ( 2 de febrero de 1933), pp. 149-150.

${ }^{63}$ El subrayado es nuestro.

${ }^{64}$ Carta 66 (3 de febrero de 1933), pp. 154-155.

${ }^{65}$ Op. cit., p. 301. 
nas, tiempos;/ los reemplaza por cielos/intemporales. Andas, ando/ por entre escombros/ de estíos y de inviernos/ derrumbados. Se extinguen/ las normas y los pesos») ${ }^{66}$ :

El poema es lo que te decía ayer y lo que te decía anteayer y el otro: la tregua, la paz, en la lucha entre tenerte, entre sentirte, como te tengo y siento en tus cartas, y no tenerte en mi ser total, la satisfacción y la insatisfacción hermanas ${ }^{67}$.

El primer poemario de la trilogía salió a la luz a finales del año 1933. Katherine, no obstante, ya tenía las pruebas de imprenta que el poeta le había hecho llegar en el mes de febrero («Porque deseo que tengas ese poema en todas sus formas, que asistas a ellos en todas sus fases de vida, desde el no ser al manuscrito, a las pruebas, a la revista, al libro») ${ }^{68}$.

Salinas considerará su libro como «el que más contento me tiene, el que más directa y hondamente me expresa» ${ }^{69}$. Posteriormente escribirá:

Katherine, tú sabes tan bien como yo que nuestro ${ }^{70}$ libro es el mejor de los míos. Yo lo supe enseguida. Hubiera sido un terrible fracaso el que los versos escritos en la cúspide de mi vida y de mi sentimiento, escritos con mi ser entero fuesen «menos» que los que escribí por el esfuerzo de mi inteligencia o de pasajeras intuiciones. Yo necesitaba creer en la profunda fidelidad de mi vida y mi creación. Existía antes, claro, el color Pedro, que tú vives. Pero, Katherine, no el poema. Yo jamás me creí capaz de escribir un poema: poesía, sí pero mi conjunto poemático, entero, de una «pieza», no. Yo lo he escrito sin proponérmelo, sin ánimo alguno de secuencia, de continuación, de unidad, porque así ha salido. Tú eres, Katherine, tú, tu amor, el que me ha dado esa unidad, ese tono de fidelidad a su sentimiento, de vivir «de él». Tú me has hecho, no en mi poesía sino en todo yo, «encararme» con la vida, mirarla frente a frente, con la mirada recta, verla en toda su profunda alegría y su profunda tragedia ${ }^{71}$.

Salinas reconoce que sus poemas no son «pensados ni elaborados». Son un diálogo con la persona amada, innombrada en unos versos «sencillísimos» cuya desconocida identidad ha despertado la curiosidad de la crítica: «...prepárate este invierno a más y más chismes. ¿Sabes por qué? Por el libro. Ya te dije que muchos le buscaban clave. $\mathrm{Y}$ dado mi género de vida y carácter, claro es, no se la encuentran. No hay mujer alguna en quien pueda recaer la sospecha. [...]. Todos los críticos dicen que el libro es muy

${ }^{66}$ Op. cit., p. 142

${ }^{67}$ Carta 88 (19 de marzo de 1933), p. 199.

${ }^{68}$ Carta 76 (20 de febrero de 1933), p. 175. En el ejemplar que posteriormente Salinas hará llegar a Katherine el poeta escribirá a modo de dedicatoria: Inseparables en él siempre. Carta 109 (14 de febrero de 1934), p. 248.

${ }^{69}$ Carta 100 (7 de septiembre de 1933), p. 225.

${ }^{70}$ El subrayado es nuestro.

${ }^{71}$ Carta 113 (20 de marzo de 1934), pp. 259-260. 
humano y la gente se inclina a relacionarlo con alguien. No lo preguntan, claro, por discreción, pero se nota como una interrogación tácita. Miran alrededor buscando la protagonista. $Y$ al no encontrarla calculo que se aumentará mi carácter misterioso. Y quien sabe si alguien acudirá a ti, a ti, precisamente, a decirte que hay una mujer verdadera detrás de mis versos y que nadie la conoce» ${ }^{72}$.

Después de la publicación del libro, Salinas reconoce haberse quedado como «suspenso, atónito» en su poesía. Si hay algo que tiene claro es la altura alcanzada tanto en su vida como en sus versos y todo, no podía ser de otra manera, gracias a Katherine:

Mi vida, desde que te quiero, está «más alta». Tiene más luz, ve más, siente como un aire más puro, y más difícil. [...]. Mi poesía, Katherine, es más alta ahora [...]. Y ya no «quiero bajar». Katherine, me sería muy triste descender de esa altura. La he «probado», he gustado su pureza, su energía vital, su claridad. Y como tú decías, alma, no me bastará con darme entero, habré de crear «más yo» ${ }^{73}$.

El segundo libro de la trilogía, Razón de amor, se publicó en junio de 1936 en la madrileña editorial Cruz y Raya. El 5 de junio Salinas, que por entonces está corrigiendo las pruebas, refleja su descontento ante la informalidad del impresor, el poeta Manolo Altolaguirre: «Llevo dos o tres días de infierno verdadero. He perdido color, he adelgazado, me he vuelto más malhumorado, tengo los nervios de punta, ya no sé lo que soy. [...]. Manolo Altolaguirre, muy buen amigo y poeta, muy buen impresor, es un insensato, incapaz de calcular nada, sin noción alguna del tiempo. [...]. Es la informalidad y la inexactitud españolas elevadas a categoría de vida y conducta. El pobre no puede remediarlo: pone todo su entusiasmo y empeño en hacer mi libro bien, pero no va a despojarse de su temperamento» ${ }^{74}$.

El 28 de junio de 1936, Salinas escribe a su «Pastora de milagros» ofreciéndole el libro «que sale hoy». Afirma no gustarle demasiado la encuadernación pero «de todos modos, yo, alma, he puesto en este libro lo mejor de mi espíritu, y lo he puesto todo, todo para ti. Al ofrecerte este libro hoy, con toda la humildad del que querría ofrecerte no ese libro sino la totalidad de sus días y sus fuerzas, me doy cuenta de que es el libro más nuestro posible. Más que $L a$ voz» ${ }^{75}$.

${ }^{72}$ Carta 111 (14 de marzo de 1934), pp. 254-255.

${ }^{73}$ Carta 113 (cit.), p. 260. Años más tarde (1938) el poeta, intentando justificar las traducciones de K.W. de sus poemas, escribirá: «O si no, demos simplemente la justificación verdadera: que esos poemas de ti nacieron, por ti se escribieron, para ti viven más que para nadie y sólo tú puedes entenderlos hasta el fondo». Carta 138 (11 de noviembre), p. 330 .

${ }^{74}$ Carta 123 (5 de junio de 1936), p. 283.

${ }^{75}$ Carta 125 (28 de junio de 1936), p. 287. 
En este segundo poemario el poeta nos explica ${ }^{76}$ una experiencia amorosa sólo mostrada hasta ahora en un tono de meditación más apacible, sobre un vivir ya edificado ${ }^{77}$ en un «nosotros» que sustituye a los pronombres tú y yo del primer libro: «este convivir- señala Alma de Zubizarretareflejado en el diálogo y logrado gracias a él y desde él, culminará en la indisoluble unión de ambos, en la creación de un nuevo ser, que trasciende la suma de las dos individualidades y la existencia de una criatura nueva: nosotros, desde el cual aparecen escritos un gran número de poemas de Razón de amor. Y para el poeta esta unión dialógica será la salvación» ${ }^{78}$.

Salinas reconoce que todos los poemas de este libro han sido escritos en un estado de «colaboración total» que no pudo tener el primero. La sorpresa por el encuentro fortuito del amor ( «Yo no necesito tiempo/ para saber como eres:/ conocerse es el relámpago») ${ }^{79}$ deja ahora paso a un análisis más sosegado de los sentimientos:

En aquél, yo escribí algunos poemas «solo», sin saber si iba a tener que seguir solo siempre: tú eras mía y no lo eras, podías echarte a volar, en cualquier momento. Por eso allí hay más dudas, «más soledades». En éste, Katherine, todo es «compañía». Lo hemos escrito los dos, tú a mi lado, en todo instante. Todos estos poemas son formas de «tu posesión de mí». [...]. Cada uno de esos poemas es, Katherine, como una pequeña isla de mundo, islas vírgenes donde tú y yo hemos vivido, solos, cuyo suelo no han pisado otras plantas. [...] ojeando el libro me doy cuenta de que «su tema» dominante es «la pareja», la unidad de «dos», es el gozo supremo de ser y ser, superando sus diferencias, sus limitaciones, sus «separaciones» en la suprema fusión del amor. Este libro, Katherine, «nos es» fiel, «me» es fiel, «te» es fiel. Nada digo, nada sé, de un valor literario. Pero como expresión de mi vida yo no puedo quitar una sola palabra de él. «Así» he amado y así amo ${ }^{80}$.

La cita es larga pero interesante para conocer de primera mano qué mueve interiormente al poeta para escribir unos versos presagiados y confirmados en varios pasajes del epistolario. Tal ocurre con el poema titulado «Nadadora sumergida» ${ }^{81}$, que Salinas había publicado en marzo de 1933

\footnotetext{
${ }^{76}$ Montserrat ESCARTín, op. cit., p. 34.

77 Jorge GuILlÉN, op. cit., p. 26. En una carta fechada el 16 de enero de 1934 Salinas confiesa a su amada: «Me enamoro día a día con más razón de amor», p. 233.

${ }^{78}$ Cito según Francisco Javier DíEZ DE REVENGA, «Introducción» a Pedro Salinas, Poemas escogidos, Madrid, Espasa-Calpe, 1991, p. 31.

${ }^{79}$ Poema 12 de $\mathrm{La}$ voz (cit.), pp. 131-132.

${ }^{80}$ Carta 125 (cit), pp. 287-288.

81 «Nadadora de noche, nadadora/ entre olas y tinieblas./ Brazos blancos hundiéndose, naciendo,/ con un ritmo/ regido por designios ignorados,/ avanzas/ contra la doble resistencia sorda/ de oscuridad y mar,/ de mundo oscuro./ [...] Y el rítmico ejercicio de tu cuerpo/ soporta, empuja, salva/ mucho más que tu carne. Así tu triunfo/ tu fin será, y al cabo, traspasadas/ el mar, la noche, las conformidades,/ del otro lado ya del mundo negro,/ en la playa del día que alborea,/ morirás en la aurora que ganaste». Poema 33 de Razón de amor (cit.), pp. 318-319.
} 
en el periódico madrileño $E l$ Sol en una nueva sección de poesía inaugurada por Juan Ramón Jiménez. El poeta le recuerda a K.W. cuánto de «nuestro» tiene el poema, escrito en Alicante a las dos semanas de su decisivo conocimiento. La composición «representa de modo simbólico muchas cosas» que Salinas no duda en desvelar:

\begin{abstract}
La nadadora eres tú. Yo sabía que nadabas. En todo el poema hay la idea de una mujer bella y fuerte (así te vi enseguida, ¿te acuerdas?), la nadadora. Pero yo trasladaba toda esa fuerza al servicio de algo sumamente difícil y superior, al servicio de la salvación de un alma entre «olas y tinieblas». Yo infundía mi propio afán, mi deseo de luchar contra las resistencias enormes, en tu cuerpo. Yo nadaba en tu cuerpo, vivía en él, luchaba con él, me salvaba por él. ¿Pero me salvaba? Yo no podía creer entonces que tú me ibas a querer, que mi amor se lograría en felicidad, veía nuestro amor como un alba, una aurora, apenas ganada y ya perdida. "Morirás en la aurora que ganaste». Y yo quería eso, morir en esa aurora, morir en la ilusión de la luz que habíamos conquistado con tu fuerza física, rítmicamente, harmónicamente [sic] ejercitada $^{82}$.
\end{abstract}

Largo lamento, tercer volumen de la serie, fue redactado por el poeta durante su exilio en América. El autor no publicó de este libro, ya escrito en 1938, más que algunas poesías viendo las restantes la luz después de su muerte.

«Poco a poco - escribe Jorge Guillén - sin ruptura, sin culminación de ruptura, van cambiando el ambiente y el tono entre ironías y quejas, cada vez más amargas. [...]. Lentitud, pero cabizbaja, melancolía, sarcasmo, depresión, muerte de aquella voz a ella debida» ${ }^{83}$.

Si La voz a ti debida era «un camino hacia el amor» y Razón de amor un «canto en el amor», Largo lamento, vendría a representar «el alejamiento y el reencuentro imposible» ${ }^{84}$.

En definitiva, en este conjunto unitario de poesía amorosa, «se observa una línea que va desde el nacimiento de la pasión hasta la despedida [...]. Separación material, porque el «dolorido sentir» ya no se lo podrán quitar nunca al amante, y Ella le acompañará como una sombra, a veces tan material, que el estremecimiento que el poeta siente con esa "presencia» se nos comunica y contagia. Pero es una sombra, habla de una sombra. De Ella ha quedado una ausencia habitada por una sombra, y Él no es, desde luego, un cuerpo habitado» ${ }^{85}$.

Esta línea descendente que la crítica ha observado en los versos salinianos, la advertimos también nosotros en el epistolario donde ya a partir del

${ }^{82}$ Carta 91 (24 de marzo de 1933), pp. 205-206.

${ }^{83}$ Op. cit., pp. $28-29$

${ }^{84}$ Francisco Javier DíEz DE REvenga, op. cit., p. 32.

${ }^{85}$ Pedro Salinas, La voz a ti debida. Razón de amor. Edición de J. González Muela, Madrid, Castalia, 1969, p. 16. 
año 1938 comienza a reflejarse cierto distanciamiento entre los amantes y una conciencia de fracaso por parte del poeta:

\begin{abstract}
Yo, Katherine, no soy un problema activo, exterior para ti, ya. Comprendo que he fracasado. Lo escribo sin el menor rencor ni amargura. He fracasado doblemente. ¿Qué te he ofrecido? Todo el amor de que soy capaz. Tengo el orgullo de creer que soy capaz de mucho amor, Katherine. Creo que mi naturaleza está hecha para amar, y a nadie he amado como a ti. Pero ese amor ha fracasado: primero porque no he podido hacerte feliz, cumpliéndose totalmente en lo exterior e interior, casándonos ${ }^{86}$.
\end{abstract}

Quizá la mejor prueba del aludido alejamiento sea la decisión de Katherine Whitmore de casarse con Brewer Whitmore, compañero en Smith College, el 23 de marzo de 1939. Cuatro años más tarde, Katherine quedará viuda tras el fallecimiento de su marido en un accidente de automóvil. Por entonces Salinas residía en Puerto Rico y se abre un largo silencio epistolar entre ambos hasta el 9 de febrero de 1946 en que el poeta justifica este vacío de tantos años a causa de la censura vigente durante la Guerra Mundial:

Una carta era una jugada de incalculables consecuencias, Katherine. No puedes figurarte lo que dudé, lo que luché, lo que sufrí. ¡En esos momentos, cuando más necesitabas tú palabras amigas, desinteresadas, recuerdo, consuelo, compañía! ¡Cuando yo más deseaba servirte de algo en tu pena! Pero no había remedio. Al contrario, tuve la sensación de haber escapado a un peligro, al ir enterándome de todo este juego de la censura ${ }^{87}$.

Precisamente, desde Puerto Rico Salinas escribiría los versos de El contemplado ${ }^{88}$. "Aún hoy —-seguimos a Jorge Guillén-, es menester justificar al poeta que mira al mar y lo dice bien. En época de bélico despropósito son más imprescindibles algunos minutos de pausa ante un espectáculo no corrompido por el desorden. No se trata de purificación sino de respiración [...]. Acogido a un rincón apartado del Club (Asociación Fraternal de Amigos), contemplaba el mar y redactaba estos versos ${ }^{89}$ ( $«$ De mirarte tanto y tanto,/ del horizonte a la arena,/ despacio,/ del caracol al celaje,/ brillo a brillo, pasmo a pasmo,/ te he dado nombre; los ojos/ te lo encontraron mirándote.»):

Y ahora... esta isla es un encanto. Sol, luz maravillosos. Un mar de hermosura constante, lleno de espumas alegres. La temperatura, para algunos un poco demasiado calurosa, a mi me gusta mucho. Vive uno con las ventanas abiertas de par en par, diez meses al año, día y noche. Y ahora, en febrero y marzo, se cierra la mitad a la hora de dormir. El gabán es desconocido. Clima sin

${ }^{86}$ Carta 131 (17 de junio de 1938), p. 302

${ }^{87}$ Carta 150 (9 de febrero de 1946), p. 368.

${ }^{88}$ México, Stylo, 1946.

${ }^{89}$ Op. cit., p. 32. 
igual para el que no necesita como yo ir y venir mucho, agitarse. He pasado horas hermosísimas frente al mar. He escrito un poema, (un conjunto de quince poemas) sobre ese mar de Puerto Rico ${ }^{90}$.

En este momento, la relación entre Pedro Salinas y la joven profesora ha sufrido grandes cambios. El poeta no encuentra a su amada ni en el presente, ni en el pasado, ni en el futuro. La angustia del tiempo ha desaparecido y flota sobre una ausencia quizá demasiado larga, «sin prisa ni lentitud, fuera del cómputo. Ahora ya eres completamente incalculable. Estás más allá del error de cálculo» ${ }^{91}$.

La última vez que Pedro y Katherine se vieron fue en la primavera de 1951, año del fallecimiento del poeta. Muchos años después K.W. escribiría sobre la riqueza de aquel «amor en vilo»:

Fue emocionante, alegre, devastador y triste para ambos. Verdaderamente, tenía «Beauty and Wonder and Terror» [«Belleza y Asombro y Terror], cita del «Epipsychidion» de Shelley que sirve de prefacio en «La voz a ti debida». Cuando releo sus cartas después de tantos años y paso las páginas de los exquisitos volúmenes que encuadernó especialmente para mí, me pregunto cómo el destino pudo ser tan amable.

El final fue triste pero inevitable. Quizás hubo un «Error de cálculo», tal como sugiere uno de sus poemas. O mejor, «Error sin cálculo». Como quiera que fuera, sucedió y fue glorioso en su momento. Acabó sin amargura. El cariño que sentíamos el uno por el otro no podía morir. Él me ayudó en más maneras de las que puedo contar y estoy infinitamente en deuda con él. Y yo, ¿qué le aporté yo a él? Fuera un error o no, fui yo quien le dio el ímpetu para crear su mejor poesía en las alegrías y en las penas. Ambos deberíamos estar satisfechos ${ }^{92}$.

\section{BIBLIOGRAFÍA}

Alonso, Dámaso, «La voz a ti debida», Diablo Mundo, 6, 2 de junio de 1934, pp. 3-4. Bou, Enric, «Escritura y voz: las cartas de Pedro Salinas», Revista de Occidente, noviembre de 1991, pp. 13-24.

${ }^{90}$ Carta 150 (cit.), p. 369.

${ }_{91}$ El subrayado es nuestro. Carta 149 (21 de julio de 1941), p. 364. «Error de cálculo» es el título del poema 10 de Largo lamento (cit.), pp. 494-503. «QQué solos, sí, qué púdicamente solos/ estábamos allí, en el fondo del vacío/ que muchos seres juntos crean siempre,/ en el salón del bar de moda adonde entramos/ a hablar de nuestras almas, rehuyendo/ con gran delicadeza/ la tramoya usual/- lagos, playas, crepúsculos-/ que los amantes nuevos buscan!». La explicación a este poema la encontramos en una carta escrita por Salinas el 26 de julio de 1937: «Ya sabes el proyecto que tenía de dar forma poética a una situación que se ha repetido mucho en nuestras vidas, y que es hablar de las cosas más profundas de ella en un sitio público, en una atmósfera poblada de conversaciones y gentes superficiales, por una especie de pudor o delicadeza al revés, de sentirnos protegidos por esa capa de lo público y lo impenetrable de nuestro secreto de almas», op. cit., p. 296.

${ }^{92}$ Katherine WhITMORE, «La amada de Pedro Salinas», op. cit., p. 384. 
CARreño, Antonio, «Los mitos del yo lírico: La voz a ti debida de Pedro Salinas», La Torre (N.E.). Revista de la Universidad de Puerto Rico, abril-junio, 1993, pp. 189-212.

Feal DeIBE, Carlos, La poesía de Pedro Salinas, Madrid, Gredos, 1965.

GUILLÉN, Claudio, «Al borde de la literariedad: literatura y epistolaridad», Tropelías. Revista de Teoría de la Literatura y Literatura Comparada, 1991, pp. 71-92.

- «El pacto epistolar: las cartas como ficciones», Revista de Occidente, octubre de 1997, pp. 76-98.

LóPEZ BARAlT, Luce, «Melibeo soy: La voz a ti debida de Pedro Salinas como reflexión ontológica», La Torre (N.E.). Revista de la Universidad de Puerto Rico, octubre-diciembre, 1994, pp. 563-599.

MARICHAL, Juan, «Pedro Salinas: la voz a la confidencia debida», Revista de Occidente, 1965, pp. 154-160.

SAlinas, Pedro, Cartas a Katherine Whitmore. Edición y prólogo de Enric Bou (2. ${ }^{a}$ edición), Barcelona, Tusquets, 2002.

- Mundo real y mundo poético, ed. de Christopher Maurer, Valencia, Pre-textos, 1996.

- Ensayos completos, Madrid, Taurus, 1983.

- Poesías completas. Con un «Prólogo» de Jorge Guillén, Barcelona, Seix Barral, 1971.

- La voz a ti debida. Razón de amor. Largo lamento. Edición de Montserrat Escartín, Madrid, Cátedra, 1999.

- Poemas escogidos. Edición de Francisco Javier Díez de Revenga, Madrid, EspasaCalpe, 1991.

- La voz a ti debida. Razón de amor. Edición de Joaquín González Muela, Madrid, Castalia, 1969.

Shelley, P. B., Defensa de la poesía, Barcelona, ed. Península/ed. 62, 1986.

SORIA OlmEdo, Andrés, «Dos voces a nivel», Pedro Salinas-Jorge Guillén, Correspondencia (1923-1951), Barcelona, Tusquets, Colección Marginales 120, 1992, pp. 9-34.

ZardoyA, C., «La otra realidad de Pedro Salinas», en A.P. Debicki, (ed.) Pedro Salinas, Madrid, Taurus, 1976. 


\section{RESUMEN}

Algunas notas sobre la proyección literaria en el epistolario de Pedro Salinas a Katherine Whitmore, por Clara Eugenia Peragón López.

La amada innombrada en la trilogía de poesía amorosa de Pedro Salinas ( $L a$ voz a ti debida, Razón de amor, Largo lamento) se presenta con nombre propio en el conjunto de cartas enviadas por el poeta a Katherine Whitmore. A través del análisis de este fascinante epistolario podremos establecer una estrecha relación entre el mundo real y el mundo poético saliniano. Su contenido nos revelará un doble aspecto documental y literario y nos acercará a uno de los mejores poemarios de temática amorosa del siglo xx.

Palabras clave: Pedro Salinas, Katherine Whitmore, poesía, epistolario, mundo real, mundo poético.

\section{ABSTRACT:}

Pedro Salinas' lover with no name that appears in his trilogy in loving poetry ( $L a \mathrm{voz}$ a ti debida, Razón de amor, Largo lamento) is presented with her own name in the group of letters sent by the poet to Katherine Whitmore. Through the analysis of these fascinating texts we will be able to establish tight relationship between his real world and his poetic world. Their content will reveal us a double documental and literary aspect of one of the best poems of love of the $\mathrm{xx}$ century.

Words key: Pedro Salinas, Katherine Whitmore, poetry, letters, real world, poetic world. 